\title{
Can GIS Foster Conscious and Critical Learning in Geography? An Application from Students to a Real Case Included in the National Strategy for Inner Areas: Monti Dauni, Apulia (Italy)
}

\author{
Marilena Labianca (D) \\ Dipartimento di Economia, Università di Foggia, Via Romolo Caggese, 1, 71121 Foggia, Italy; \\ marilena.labianca@unifg.it
}

check for updates

Citation: Labianca, M. Can GIS Foster Conscious and Critical Learning in Geography? An Application from Students to a Real Case Included in the National Strategy for Inner Areas: Monti Dauni, Apulia (Italy). Sustainability 2021, 13, 9246. https://doi.org/ $10.3390 /$ su13169246

Academic Editors: María Luisa de Lázaro y Torres and Chunjiang An

Received: 10 July 2021

Accepted: 16 August 2021

Published: 18 August 2021

Publisher's Note: MDPI stays neutral with regard to jurisdictional claims in published maps and institutional affiliations.

Copyright: (C) 2021 by the author. Licensee MDPI, Basel, Switzerland. This article is an open access article distributed under the terms and conditions of the Creative Commons Attribution (CC BY) license (https:/ / creativecommons.org/licenses/by/ $4.0 /)$.

\begin{abstract}
Digital technologies, the use of which has progressively increased over the last few years, could represent key tools in learning and active citizenship in development processes. In this sense, Geographical Information Systems (GIS) have gradually become an integral part of various disciplines and sectors. Even if the relevance and diffusion of GIS in the educational and pedagogical fields are increasing, their potential is still under-explored in the development of empowerment for participatory planning. Regarding the combination of geographical education and information technologies applied to the territories, the contribution they offer to the Sustainable Development Goals (SDG) is a question which remains little-investigated, and which represents both an innovative field of experimentation and significant opportunities, especially for marginal, inner areas. However, recent reforms, in particular in Italy, are considerably reducing the role of geography in the curricula, which is paradoxical for such complex contexts and the understanding of major global issues. The risk is that of producing a gap between the functional use of the tools and the capacity for their critical application. This paper aims to reflect on the integration of Geography and GIS through teaching experimentation, as applied to a real case study in the Apulia region (Monti Dauni Area) under the national strategy for inner areas, in order to understand how to use GIS as an active tool in education for sustainability, the awareness of the value of local resources, and active citizenship.
\end{abstract}

Keywords: geographical information systems; geography; education for sustainable development; Italian strategy for inner areas; Monti Dauni

\section{Introduction}

In recent years, the use of Geographical Information Systems (GIS) has spread significantly, developing from a tool in the hands of a select few to gradually become an integral part of various disciplines and sectors. When seeking the areas of application of GIS, a keyword search on the Google Scholar portal produces over 2,000,000 results for "GIS application". There are applications in different disciplines and fields: from applied sciences in space and geography through to economics (with a strong focus on agriculture and services such as tourism and transport), the environment (with particular attention to prevention models and environmental disasters), engineering, urban systems and education.

In this context, education is a sector that is still under-explored, while there is growing attention from the social sciences. In various cases, it is clear that the cognitive goals are very ambitious, not being confined to merely descriptive aspects but often making use of sophisticated forecasting and predictive analysis tools and, more recently, adopting a purposeful approach aimed at the development of empowerment through participatory mapping in development planning; see [1-5].

A Geographic Information Systems (GIS) is known to be a complex, organized set of data, software, hardware and networks in the broad sense of the term, the aim of which is to collect, analyse, remodel, manage, update, store, represent and transfer different 
types of spatial information. Its special advantage is that it gives a territorial dimension to information that does not possess this characteristic, and it makes it easier to question existing knowledge and produce new knowledge independently.

The evolution of GIS and its related applications has not been quick or simple, and it is still not free from debate, as Goodchild [6] points out. In fact, research in the 1980s was still firmly anchored to solving purely technical problems and issues, starting from the assumption that, in the scientific tradition, GIS should be merely limited to questions of measurement. It was only in the late 1990s that a radical change occurred, as researchers began to realize that the problem was not one of simple measurement. This shift marked a deeper transition, from a perspective centred on the processing of map contents, to the much broader and more complex one of an approach to the entire process of representing and characterizing the "geographical world". Another major challenge was to find ways of representing the infinite complexity of the real geographic world in a limited space, and of translating it from an IT point of view. The last few decades have been important, and have focused attention on the "nature of the geographic world, and the ways in which it influences effective GIS design" [6] p. 12, thus producing significant changes at the level of application technology. This has, in fact, involved the development of methods increasingly based on local or place-based territorial analysis, providing an important contribution of the knowledge and technical means to investigate the specific characteristics of places, thus bringing the issue of territorial heterogeneity to the fore.

Since the 1990s, GIS has increasingly gained a reputation as a software for use in the public and private domains with significant potentialities (in terms of spatial analyses, the information obtained thanks also to incorporated applications like plugins, as created both by the developers and by other independent users), enabling the software's basic functions to be greatly expanded (see for example Quantum GIS software and its international community). Moreover, trying at the same time to draw an ideal line showing the advances in mapping, planning and territorial development tools, it can be said that there has been a paradigm shift in terms of democratization in the use, reuse and production of data and information, and therefore an increasingly clear orientation towards active participation in the construction of new knowledge. This change was also stimulated by the most recent development policies. Emblematic in Italy is the example of ISTAT, which has developed specific themed indicators for policies and programming cycles. In 2021 the databank contained 327 indicators ( $258+56$ gender-based) which were available at different levels and for historical series starting from 1995 up to the last available year. The goals include the possibility of having updated territorial data and indicators to observe the results achieved by the various policies in the territories, and possibly intervening through the rescheduling of resources [7]. On this point, we must think not only in terms of the dissemination of data and information (made public and therefore no longer confined to select users) but also in terms of the collection of such data, which is increasingly oriented towards bottom-up and participatory processes (as has been happening for some years with the Italian Institute of Statistics, especially for the indicators of Fair and Sustainable Wellbeing, which places Italy at the forefront of the international scene regarding indicators of the state of the health of a country that go beyond GDP) [8].

As such, while it is true that Geographic Information Systems (GIS) are recognized as being among the 25 most important developments that influenced human life in the 20th century, it is also true that this tool has so profoundly revolutionized the methods of spatial analysis that Geography has become an important discipline in other areas characterized by a strong spatial component, such as Political Science, Planning, Geology and Sociology, etc. [9]. These developments, especially the more recent ones, call into question the issue of geographic education.

In particular, in the 1980s and 1990s, reforms in geography education had already been introduced, first at the university level in the United States and Canada, which made the subject an integral part of the Geography departments in most universities in the USA and Canada, with specifically work-oriented courses. This is, however, still on a small 
scale and is largely confined to specific fields, especially in various European areas [9]. National policies, the allocation of funds and resources by universities, and a prevailing productivistic and predominantly technical approach are considerably reducing the weight of geography in the curricula, increasingly downsizing it to an "invisible" subject. In fact, although its relevance is acknowledged in the understanding of major global issues such as climate change, environmental degradation, natural hazards, inequality and geopolitical conflicts, etc., and though there has been a recent "spatial" shift in various disciplines, this does not automatically lead to a greater recognition of its importance [10]. On the one hand, therefore, we are witnessing the key role of geography in international agendas; on the other hand, we are also witnessing its dramatically reduced importance in the education of students who will be future citizens. The current approach, which places little emphasis on territorial dynamics, leads to the exacerbation of the purely economic and financial aspects, and the underestimation of the local realities with identity problems.

The growing interest in Geography is clearly shown by the international and European observatories who deal with the implementation, evaluation and orientation of development policies in order to bring out evidence, criticalities, diversities and territorial impacts. We can consider the applied research, the tools developed and made available at different scales, and the rapid spread of open tools with extraordinary interactive and dynamic web-mapping potential-see for example the European ESPON Observatory (European Spatial Planning Observatory Network), EUROSTAT for Europe and ISTAT at the national level, which have strongly implemented the traditional basic functions of simple data mining with geo-visualization tools which are often interactive, customizable and dynamic.

In the field of geo-technology and GIS, the professional prospects are therefore quite interesting, but this does not translate into a growing importance and popularity of Geography; on the contrary, it could cause a further fragmentation of the discipline and a standardization if training and education focus exclusively on technical and job-related aspects. All of this requires a profound reflection on Geography, its increasingly pervasive relationship with GIS and new technologies, and its teaching methods, contents and objectives. It becomes essential to focus on education and initial training in order to avoid a dangerous gap between the development of these technologies, with the rush to digitization (see above all the European objectives in the current programming cycle), and on the other hand, the undermining of geographical education, as exacerbated by the most recent reforms which have also seen a considerable reduction of the teaching of Geography at all levels of the Italian school system.

A major aspect that has greatly increased the relevance and diffusion of GIS is its educational and pedagogical potential, among others [5,9,11,12]. As Azzari et al. [12] underlined, if it can be called a revolution, it has been pervasive and important. In fact, there has been a shift from the simple possession of geographic information and concepts (often theoretical) to the possibility of making such information useful. In other words, it means becoming capable of organizing data and information in order to produce geographic knowledge, and to act geographically and globally thanks to the great potential of GIS, which allows us to understand social, economic and cultural phenomena in complex situations [12]. There are various reasons for including GIS in Geography teaching: from the ability to view, manage and analyse geographic data and organize them on a map, through to the ability to teach geographical thought and research [12]. This tool therefore enables us to teach how to understand space and place, to elaborate conceptual models of reality, and to study a context by selecting useful data, interpreting and representing them effectively [12], so that it can certainly be oriented towards Education for Sustainable Development under Agenda 2030.

It is important to keep in mind that a fundamental role is certainly played by the final user. As we know, this is by no means neutral and inevitably reflects the point of view of the observer, who becomes an active protagonist in the choice of the phenomenon to be investigated, in the selection of the data and in their processing, inevitably bringing out the 
approach (geographical) consciously or unconsciously adopted in the description of the contexts under study. The approach adopted, as discussed in a recent work [13], reveals governance styles, especially on a local scale, and inevitably influences the strategies, proposals and interventions in the area. It is therefore an important step that requires deep reflection on the conscious, critical use of these tools. The combination of geographical education and information technologies applied to the territories, and the contribution they offer to the Sustainable Development Goals (SDG) are questions which remain little-investigated, and which represent both an innovative field of experimentation and significant opportunitiesespecially for marginal, inner areas, among others-in particular [14]. Starting from these considerations, the present study, through literature and key programming documents, aims to reflect on the methods of integration between Geography and GIS, and, by means of a teaching experiment, to understand how to consciously use GIS in the best possible way as an active tool in education for sustainability, awareness of the value of local resources, and active citizenship. This experimentation, developed during research and teaching activity in recent years, adds a further element of innovation, and in fact was conducted in the context of a specific, real subject, with the presentation of a case study on an area of national strategic importance (Monti Dauni in the Apulia region) in the domain of development policies in the current programming cycle.

\section{How Are GIS, Participation and Citizenship Related? The State of the Research Field}

Recent trends in the teaching and use of GIS have encouraged innovative and flexible forms, and have urged greater attention to socio-cultural contexts for learning and knowledge building. In fact, as Tate and Jarvis [15] underline, in the literature about learning, more and more often one finds terms such as "participation", "construction" and "in progress" rather than "acquisition", as the latter refers more to a traditional conception of learning, seen as "the rational process of the individual student acquiring context-free propositional knowledge". This involves a traditional, formal, codified type of knowledge requiring the teacher to continuously transfer knowledge and skills to the students. By contrast, more recent approaches see learning as a work in progress through the participation and construction of knowledge in situated social settings. Such a process takes place not only in formal education but above all in different areas, taking on a significant informal dimension. The use of specific technologies, in appropriate and collaborative contexts, should therefore allow us to move from merely transmitting information to constructing active knowledge [15]. In this regard, as stated by Krasny and Tiball's civic ecology model [16], various lines of research provide indirect evidence of how specific drivers of local practice can become real drivers of social action, providing the potential for active involvement and responsibility in local political processes, promoting the commitment of residents to achieve new forms of territorial organization and objectives that are closer to community needs. In the proposed model, which has interesting practical implications, environmental education draws on the work of ecosystems and social scientists to develop frameworks in which environmental education becomes part and parcel of ongoing social and ecological processes, creating virtuous cycles and feedback between the social and biophysical aspects of the environment, ecosystem services and human health as one of the many drivers of socio-ecological processes. In this case, environmental education acts as a basic tool to improve environmental quality, which is a process requiring non-linear solutions that take into account the complexity of socio-ecological systems, as well as the importance of understanding the interactions of educational programmes, with other system components and processes. This perspective in educational programmes offers the opportunity to develop a sense of competence and empowerment by influencing environmental behaviour in engagement in a range of social actions, and in addressing larger problems (e.g., climate change or other complex current issues). In fact, the complexity of the current phenomena requires a significant rethinking in terms of policies, knowledge and practices. In a rapidly evolving context like the present one, technologies and education for sustainable development are becoming more essential, and this is evident in various 
international and European agendas; see [14,17-23]. This is increasingly indispensable in disadvantaged areas, in which the "youth are considered both as beneficiaries and drivers of sustainable development" [19] p. 12. In particular, Development Goal 4 "Ensure inclusive and equitable quality education and promote lifelong learning opportunities for all" establishes that, by 2030, all students will acquire the knowledge and skills necessary to promote sustainable development, through a culture oriented in this direction and towards global citizenship. This requires high quality teaching at all levels of training, enabling the acquisition of relevant knowledge and skills, including high quality technological, technical and professional skills, objectives that should be included in all national education policies [23]. Specifically, the Incheon Declaration [14], which strengthens the action and implementation of Goal 4, starts from reflections on the EFA goals since 2000 and the Millennium Development Goals (MDGs), and in particular considers the lessons learned, thus outlining the Framework for Action and the future priorities and strategies for its achievement. This declaration recognizes a key role for education as the main driver of territorial development. The agenda is innovative because it places a renewed vision of education at the center of attention, acts in a holistic, transformative and universal way, intervenes critically on unfinished work in the field of education, and is inspired by a humanistic vision of education and development based on human rights and dignity, social justice and inclusion, etc. It represents a strategic key to achieving full employment and the elimination of poverty and marginalization, especially in the territories most exposed to these risks.

In fact, the extraordinary dissemination of data and information by different observers, including data related to territorial areas, and their ever-growing accessibility, requires specific skills and competences for the promotion of new knowledge that can lead to innovative ideas or solutions. At the same time, there is less focus on the use of these resources, especially in terms of training. The value of open, updated and free data from the services of Spatial Data Infrastructures (SDI) and the contribution they offer to the understanding of the territory and the social responsibility related to sustainability, and therefore to the Sustainable Development Goals (SDG), is a new issue in terms of academic debate; in this sense, an interesting application can be found in a recent study [11].

The combination of geographical knowledge and information technologies applied to the territories can offer opportunities thanks to the fact that the knowledge comes from different sources, enabling transversal environments suited to collaboration to be created, analyses to be performed, and strategic choices to be made both in the private and public spheres at different levels of regional action. However, while the advances that have profoundly marked the last few decades in the field of GIS-Science, policies and planning have produced important debates in the theoretical and scientific fields, their results in terms of training applications, especially at a local level, have been less inspiring.

Thanks to the advances mentioned above, GIS has enormous potential which, however, requires expert knowledge from a cartographic and geographical point of view. It is an interesting tool oriented towards the production of personalized knowledge because it allows the user to produce maps with extreme freedom, starting from the selection of the data and variables; their combination, processing, reprocessing, visualization; and finally their cartographic production.

When reflecting on GIS as a tool or as a science, according to Goodchild [6], the most complete approach to defining GIScience consists of "The development and use of theories, methods, technology and data to understand processes, relationships, and models". In addition, on the basis of a report to the National Science Foundation (following a 1999 seminar) he argued that GIScience can be understood as "The basic research field that seeks to redefine geographic concepts and their use in the context of geographic information systems", thus making the close link with geography clear. However, according to the author [6], the real innovation lies in rethinking the increasingly predominant role of citizens. In fact, the progressive elimination of traditional barriers between expert and layman's knowledge has led to a widespread awareness of the power of GIS and 
above all of the significant contribution citizens can make to providing geographic data, a phenomenon known as Voluntary Geographic Information (VGI), crowdsourcing, participatory and community mapping. The citizen is therefore not just a passive user of data and information but becomes an actor in the production and subsequent accountability for what is produced. This is certainly a paradigm shift. The author argues that this strategic information is extremely useful not only in times of crisis and emergencies but also, above all, in coherence with our approach, to foster active citizenship and thus guide policy choices in a participatory and visionary way as part of the latest generation of spatial planning on this distinction; see [13].

Thinking of the applications of GIS in the field of planning inevitably makes us aware of an important change in dealing with a territorial context, which cannot be limited to describing and representing individual features (morphology, hydrology, economy) as if in an inventory; instead, we must try to detect local resources, explaining their connections, organization and evolution over time. Above all, emphasis must be placed on contextual recognition by the local community and by policy makers in order to design targeted, multidimensional measures that can define the shared vision of future development. These are strong connections that can play a central role in territorial regeneration and the development, above all, of marginal areas.

The values and meanings locally attributed to resources are in turn linked to particular practices, cultures and local social features [24]. The study of a territorial context, therefore, cannot be limited to describing single aspects or components, but must necessarily consider them in their complexity, integration and interaction. On the other hand, the choice made by the observer can tell us a lot about the values and meanings attributed to resources. In fact, people can be regarded as creators of places when they attribute meaning and values to space according to their personal experience and culture. These values become central to both individual and collective decision-making, and may give rise to disputes, conflicts and changes because they are not universal within a given population or region [13]. Moreover, attributing values expresses a certain importance of the object as opposed to one or more other objects [5].

As Dematteis and Giorda [25] argue:

Territorial Education sets out to combine the goals of the various forms of education (citizenship, inter-culture, sustainable development...) in a territorial dimension, rethinking and redefining them on the basis of the diversities of the places and the complexity of the geographical spaces.

This necessarily involves the need to consider all of the aspects in which the "educational perspective" has to facilitate the recognition of the diversity of territories (social, cultural, environmental, political and economic). The territory becomes a "unifying concept" because it allows us to

... relate education and society, united before the challenges of sustainable development, inclusive and participatory development, practices of citizenship, coexistence and co-evolution, with a view to planning for the future. In this way, territorial values are a fundamental concept because they make it possible to recognize the local heritage and the potential resources of places to evaluate them and to refer to them in the social construction of sustainable development [25] p. 18.

This approach therefore considers the territory as a "social project", in which there is an attempt at re-appropriation by the community. As a result, it is essential to provide an education that starts from geographical knowledge in order to achieve the goals of active citizenship and shared development. A form of education that develops an awareness of place therefore predisposes the citizen for change. If it is based on the place, but lacks geographical knowledge, it is incomplete in an approach designed to promote social justice and sustainability. In the vision of geographic education proposed by Dematteis and Giorda [25], places play a fundamental role as educational environments, but this is achieved through an awareness that comes from the language of geography, of its ability to analyse, study and understand the complex relationships between human and natural 
systems, and to control territorial transformation. The territory is therefore a complex and necessary social construction.

On this point, in the United Nations Agenda 2030 "Transforming our World: the 2030 Agenda for sustainable development" [22], education assumes a strategic role for the development of fragile, vulnerable territories. There are important conditions: it must be inclusive, fair, and of good quality at all levels and for all individuals without discrimination. Especially in the most exposed and vulnerable areas, it states the need to guarantee everyone the same opportunities, such as to acquire the knowledge and skills needed to take advantage of opportunities and to participate fully and actively in society. It also places great emphasis on competences and skills; in fact, various agendas and studies [14,17-23,26,27] have dealt with competences for sustainability and the related conceptualization. However, Education for Sustainable Development (ESD) actually requires the lifelong promotion of skills such as creative and critical thinking, communication, collaboration and cooperation, with a particular focus on conflict management, decision making, problem solving and planning, and the appropriate use of ICT in the full exercise of active citizenship in practical life. These skills are key competences that should allow for an active, thoughtful and cooperative participation for sustainability. This is "transformative social learning", which is capable of deconstructing what exists, of critically reflecting on values and world views, and of affecting traditional learning processes to achieve the construction and sharing of new meanings in order to contribute to the feasibility of the goals of sustainability [26].

In this regard, according to the authors [26], the following key skills are to be cultivated: thinking with foresight and imagining new scenarios; coping with complexity; working in an interdisciplinary way and creating a dialogue between disciplines; perceptions and capacity for contextualization in a cosmopolitan environment with cross-cultural understanding and cooperation; participatory skills; deciding and acting for change; planning and implementation; the capacity for empathy, compassion and solidarity, managing emotions and stress; self-motivation and the motivation of others; critical thinking; and the clarification of values. Despite the considerable progress in the conceptualization of competences and skills, etc., their holistic incorporation into school curricula has not been very successful. Among the obstacles, in the first place, there is a lot of terminological ambiguity about competences, skills and abilities, making it more difficult to clarify the complex (and non-linear) interconnection between all these elements. The present challenges require skills in sustainability, and therefore careful reflection on tools, methods, training and assessment. Such skills concern: individual responsibility, the ability to process information, the ability to reason on scientific phenomena, and the ability to work as part of a team. These will allow young people to interact with real life in the current contexts of contemporary society.

The approach adopted in this paper, starting from the understanding of basic geographic concepts, used GIS to seek learning outcomes in situations that directly involved the students, in such a way as to activate a path of growth and personal decision-making leading to individual actions shared within the work group. As stated in Napal et al. [26], this involves the internalization of values and other non-cognitive components. The experience chosen consists of situations that would enable the students to put into practice what they have learned, through a powerful tool strongly oriented to the free creation of knowledge, based on decisions that are personalized and therefore specific to the user. In other words, it refers to situations that provide individuals with the opportunity to use science and field knowledge that encompasses the four dimensions ("knowing", "knowing how to be", "knowing how to do", "knowing how to live together").

As emerged in a recent research study [13], specific characteristics can be identified corresponding to the planning approach (rational and spatial) related to the type of strategy, the style of the plan, the knowledge exploited, the participation and so on. This is a step forward that, in parallel, as we have previously argued, would seem to have characterized the evolution of GIS and its related applications. In correspondence with the different 
levels of territorial integration and of the approach to development, it is possible to outline the main characteristics of the participation. In fact, they can be connected to the methods of use/reuse/reprocessing of data and digital resources, passing from a passive approach of the mere fruition of information to a more active construction, with a critical, responsible reconstruction of knowledge (that is, the development of empowerment through a measure involving the participant in action and direct responsibility).

Although, as previously stated, there has been a growing diffusion and democratization of GIS tools and data, these phenomena are not counterbalanced by an equal diffusion of geographic education. The risk is that this heritage could be reduced to standardized operations, strictly applicable above all in the field of planning. The adoption of a critical approach already in the stage of the selection of the data and information is therefore essential in determining the output produced. This requires particular attention when territorial development is at stake, in which case a critical, integrated and complex work plan must be envisaged. For example, in the processes of regional planning, community demands and expectations can be many and varied, and sometimes incompatible with each other, as in the case of land use that can irreversibly modify the landscape [28]. These conflicts arise mainly because the points of view and perceptions of the different community members are different. This generates a conflict regarding the values attributed to local resources between different actors. As will be explained in more detail in the next section, through the experimentation which was introduced in a university course, we tried to reflect on the role of GIS and on the potential for the development of a greater awareness of the value of local resources by the students involved. The teaching experimentation, conducted in a particular period due to the COVID-19 health emergency, took place using desk-type analysis, based exclusively on data and sources available online.

Using a combination of theory and practice, context analyses of an area of considerable regional interest for current policies were reconstructed, with the aim of testing the tool's potential for developing critical thinking and active citizenship in a proactive key. The final products were also assessed by key figures of the sector. The students, as will be shown below, did not confine themselves to the initial description of the place under study, but in various applications they proactively defined the interventions to be implemented in the area in question. In this first experimental phase, without going into too much detail on the pedagogical and evaluation methodologies (the main reference point in this paper is the work of Ajello and Belardi [29]), it was considered useful to extract the fundamental characteristics of the proposed approaches and to verify which ones were compatible with the work underway, reserving the right to conduct more specific studies in the future.

\section{Materials and Method}

As previously discussed, the literature and the international and European programmatic agendas represented the reference point for this experimentation, particularly Development Goal 4 and specifically the Incheon Declaration [14]. The approach of this declaration is perfectly in line with the area chosen as the subject of the experimentation by the students, an area characterized by serious criticalities in terms of education and human capital. It must therefore be considered a challenge to be implemented with policies that aim at quality education, capable of fostering creativity, knowledge, and social and personal skills, and of responding consciously to local and global needs through education for sustainable development (ESD) and global citizenship education (GCED).

The experimentation, triggered by previous studies, was carried out in the course on Geographic Information Systems, a university course held in the third year of the Digital Management degree (management curriculum) at the University of Salento in the academic year 2020-2021, and it involved 40 students (24 male and 16 female students). In view of the students' lack of basic knowledge, the limited time available and the fact that the course was clearly applied and laboratory-based, specific choices were made. The first was about the commonly-felt need to have an initial "tool box" to provide the necessary guidance in organizing, selecting and using the data and information available. As Bissanti [30] p. 15 
states "the teaching-learning of Geography certainly has to do with roads, ports, business activities, plains, lakes, vegetation and other elements of the territory. It should be kept in mind that it is not a jumble of things thrown in willy-nilly, but an organized set of elements all linked by complex relations of connection and interdependence". Therefore, according to the author:

... it's necessary to clarify our ideas a little, since this is an important point, to which we should pay special attention. It is an important point because it can help us to understand the real nature of the subject. And understanding the nature of a subject, 'taking possession of its structures [ ... ], in the sense of essential concepts, fundamental principles, key ideas, methods [ ... ] is the indispensable prerequisite for knowing how to 'use' that subject as a tool to achieve great educational purposes.

In addition [30] (pp. 18-21), Geography has an important "social role" because it not only enables us to decode reality but above all to "appropriate" it for ourselves, to give "specificity to space" seen as a complex "social product", a space that "is not neutral, shapeless, an inert substratum; it is a space made geographic, it is a living space". Geography has educational purposes, and with the other subjects educates the future citizens about the value of solidarity and sustainability, and introduces them to "the scientific method".

Consistent with this approach, the basic concepts were selected, guided by some works shared among the group of students among the sources [30-41]; in particular, the students read the Italian strategy for inner areas and the local strategy applied to the real case of study on the practical experience in courses held in recent years, and on that of the present author's post-graduate activity. Special attention was given to the concepts of territorial identity, territorial capital and development in order to point the students, for their final report of research, towards the analysis of a real case which was of national interest but was little known. On this point, notice the students' lack of knowledge about strategies, practices and measures for development in Europe, Italy and especially in their own territory, the target of a major intervention in the SNAI (Strategia Nazionale Aree Interne /National Strategy for Inner Areas) [39]. The students were given the basics in cartography; cartography in fact plays the role of "summing up knowledge" and is the "product of a cultural synthesis" with great communicative power, capable of "expressing many things simultaneously" [40] (pp. 13-14). The approach was based on a series of steps, from the acquisition of the basic concepts and their assimilation, through to their application. At the end of each lesson, the students were provided with the materials discussed in the classroom so that they could study them in greater detail, along with links for further in-depth materials. This was followed by thematic debates on the topics, thus enabling the students to become active creators of their own knowledge. Starting from basic concepts and knowledge, with the help of the teacher as a facilitator, the students gradually became autonomous in their search for materials and data sources thanks to a growing responsibility for their personal learning process and the development of the capacity of independent judgment on current issues. The students progressively learned to critically read programming documents and data in preparation for local-scale application to the area under study. The application to the local case study required a progressive maturation and recognition of territorial values in the construction of the proposed project not simply as individual students but within the working group. The viewpoint adopted in the experimentation was socio-cultural, going beyond the cognitivist approach, and was achieved using participatory methods actively supported by the teacher during the teaching activities. According to Ajello and Belardi [29], this enhancement of participation takes place in activities that are, in turn, highly operative regarding the cognitive processes involved, directed to the learning of reasoning methods, and typical of "expert thought" in a specific disciplinary field. It is a guided path which explicitly brings out cognitive and reflective skills and processes in the solution of certain tasks. This approach is interesting in that it does not envisage and does not take into consideration (even in the final evaluation) the mastery of contents alone, but rather focuses above all on the way knowledge is applied, 
the features of the tools and artifacts specific to a subject area, thereby producing positive effects on the students' sense of competence and self-efficacy.

The interesting aspect of this approach is that it considers learning as an essential characteristic of human beings regardless of the activity they perform in different cultural contexts, and as something that everyone experiences, taking place thanks to the learners' participation in "situations that make sense for the individuals involved and that have an effect not only from the point of view of acquisitions in terms of contents or cognitive processes, but also for the identity aspects of self-construction" [29] p. 17.

Consistent with the approach adopted, the evaluation method was also assessed and modified in progress. It could not be of a traditional type, limited exclusively to the testing of the knowledge learned in a top-down mode. In other words, it was essential not only that the products/results of the application of the subject's contents should be clear and evident to the learners but also the whole metacognitive process to reach those competences, thus supporting self-critical reflection through the realization of more complex tasks. As Ajello and Belardi [29] argue, this also leads to an enhancement of the students' reflective and metacognitive capacity, as well as their professional growth. This approach, which is akin to the principles of the "reflective learning portfolio", calls for the discussion of the contents and choices made, and also a chronological organization of the outcomes produced in a certain time frame. All of this, according to the authors, enables the student to progressively develop awareness in mastering contents, tools and skills, thus allowing a critical comparison between the initial and final phase of the work, highlighting the process of personal growth (see Table 1).

Table 1. Main features of the socio-cultural approach.

\begin{tabular}{|c|c|}
\hline Features & Where? In What Setting? \\
\hline Enhancement of participation & $\begin{array}{l}\text { Hands-on activities in situations that are } \\
\text { meaningful for the individuals involved }\end{array}$ \\
\hline Guided experiences & Task and problem solving \\
\hline $\begin{array}{l}\text { Understanding, knowledge, tools and } \\
\text { modes of use in a field of knowledge }\end{array}$ & Focused learning \\
\hline Strong social interaction & $\begin{array}{l}\text { With peers and/or with more skilled figures, } \\
\text { within one's social group }\end{array}$ \\
\hline Production of tangible outcomes & The products are "socially recognizable" \\
\hline
\end{tabular}

This method of detection is effective if it is applied in real situations. It requires students to participate actively in all of the stages, from the selection of the information through to the final product and its discussion. GIS lends itself well to this purpose due to all of its previously mentioned features. Not only must these processes of selection, reflection and discussion be made explicit in order to allow the teacher to make assessments, but they must be clear from the beginning of the course. In order to be effective, the involvement must be subjected to continuous reflection, and must be co-constructed with the teacher in a constructive and critical way. In this process it is possible to grasp the students' ability to self-organize, to progressively identify their strengths and weaknesses, and to intervene to overcome the latter. Students also find themselves launched from a professional point of view into conducting complex activities in real situations, and are able to feel that they are the creators not only of the final product but also of their own learning path.

\section{Results and Discussion}

The starting point of the experimentation was a shared reflection during the lessons about key concepts in Geography. The first part of the course tackled some basic concepts, selected in relation to the training goals set and taking into account the students' initial level. In the second part of the course, the students were monitored in the selection, examination and representation of phenomena using three levels: descriptive, explanatory-scientific, 
and critical-applicative [30]. At the same time, examples of applications were presented with reference to regional case studies, along with sources and methods of acquiring the necessary data (including Web-GIS, which facilitates not only consultation but also interactions between different data) for the representation and description of the territorial context to be applied in the GIS environment. Consistently and in order to promote greater autonomy in setting and carrying out the assignment, an open source software was used (Quantum Gis).

More specifically, the attempt was made to analyse the students' ability to choose the data and indicators to be mapped, to process them on the basis of the chosen criteria which were shared and justified, and to discuss and support such choices (data selection through specific criteria resulting from the users' purpose-oriented choices).

The real case study examined with the students required them to apply what had been learned about the development of context analysis to a well-defined area in the region. This is the Monti Dauni area in the Apulia region (South of Italy), one of the 72 project areas selected as part of the National Strategy of inner areas [39]. It is an innovative application because it allows students to know and apply the knowledge and the skills learned during the course in a real ongoing work environment in their own territory, stimulating their interest and commitment. This aspect is fundamental because the experimentation required a significant commitment from the students and a strong sense of responsibility towards the working group in the execution of the project from the beginning to the end using a cooperative, mutual approach. For this reason, it is believed that the application to a real case study that directly involves them as citizens and beneficiaries of the policies is a key element in stimulating curiosity, commitment and the highest level of participation, i.e., empowerment. The lectures on the reasons for this intervention aimed to prompt students to carry out further research and in-depth studies, as well as to reconstruct and integrate the context analysis already present among the planning documents of the area under study; see [41]. A fundamental point of the experimentation is that the approach adopted was strongly participatory, cooperative and based on a real application to a local case, which stimulated the students to search for strategies that were-in many casesinnovative and creative in order to complete their work. Specifically, they undertook the development of methods for searching and selecting relevant data, and their representation and communication externally.

In particular, among the interesting applications, there is the example of a group of students who developed a method for extracting relevant information from programming documents through textual analysis, while another interesting case involved the autonomous exploration and deeper analysis of the interventions and projects in progress in the area in order to understand the possible impacts and the future vision of the territory. In another case, the students developed topics not addressed during the course and largely overlooked in the local strategy, such as addressing the problem of exposure to the risks of the area (social, economic and hydrogeological risks, etc.), which required further research, all of which revealed a growing development of their autonomy and critical application capacities. This required a further effort to understand and decode the information for further analysis, with the experience of in-depth study bringing the students closer to the research. This was possible thanks to the GIS working environment, which allows an integration not only between data and information but also of the methods of analysis that can be achieved thanks to previous knowledge being consolidated in a virtuous circle (for example, previous knowledge in economic geography, the geography of tourism, economics, statistics, etc.). 
Each working group, therefore, adopted different strategies in carrying out the project, thus bringing into play both previous knowledge and skills, and those learned in other courses. Once the timetable was set in the subsequent phase of the research, along with the integration and selection of the variables to be represented independently, as well as the delivery of the documents, the latter were collected in a personal archive, discussed and supported first within the working group and then with the teacher, before the final discussion in the presence of key figures of the sector (the Director and President of the Monti Dauni Area). During these phases of work, the discussion between the students and between the students and teacher were fundamental, as they raised interest and new skills relevant to the topic, thus representing a further learning experience. The particular period of the pandemic did not represent a great obstacle; the possibility of being able to organize meetings, often organized independently among students, allowed all of the members of the group to work and participate actively in all of the sessions. The creation of the GIS project was therefore gradual, and required various moments of reflection. The project was created, firstly at individual level, and then shared in the work group. It consisted of a number of non-random information layers, resulting from specific choices and demonstrating the progressive ability to decode and organize data and information, to distinguish a sequence of information layers (Figure 1), to identify and reconstruct phenomena and relationships, and finally to propose innovative solutions about strategic interventions in the territory using a research method developed by each group, of which the steps had to be indicated.

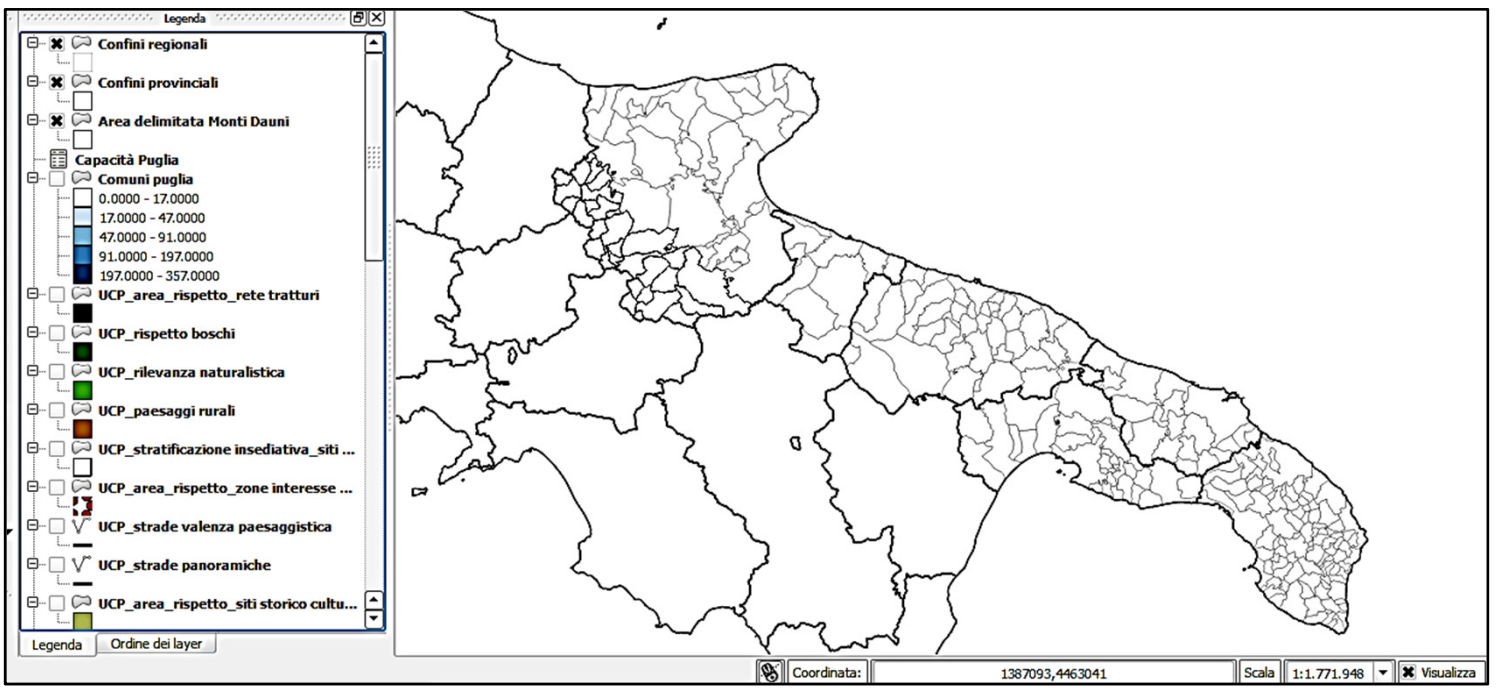

Figure 1. Example of a final project: the students used a free and open source Geographic Information System, Quantum GIS. Once the study area was defined and discussed, the information layers were selected and added by each student.

The specific process involved moving from an initial level of description (in which the information layers concerned single discrete objects recognized, classified and named) (Figure 2a), to the awareness of their space-time development in a multi-scale context, identifying relationships of growing complexity among the different data sets selected (Figure $2 b$ ), through to proposals for functional territorial development interventions in a well-defined area, with the working groups producing different outcomes. 


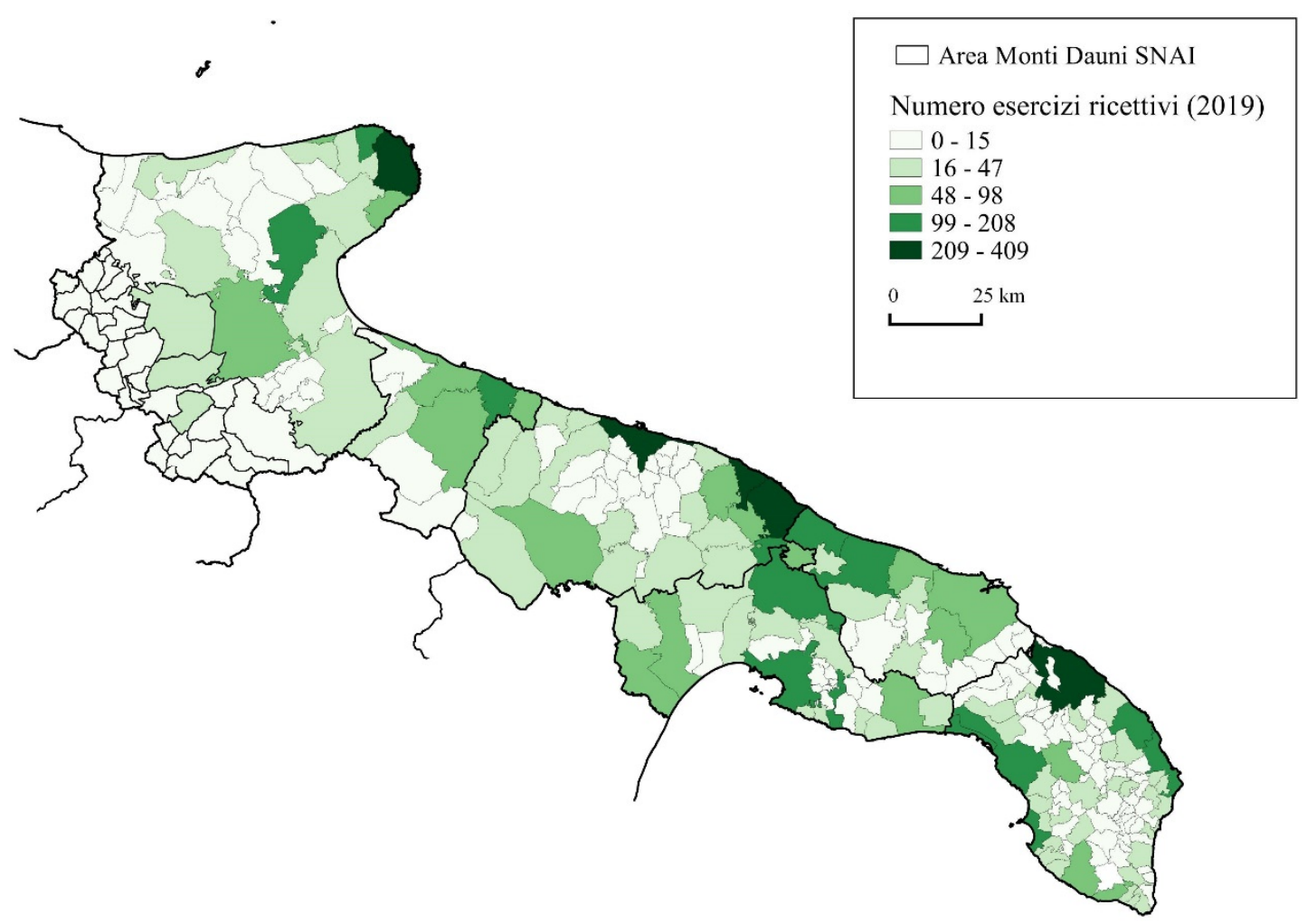

(a)

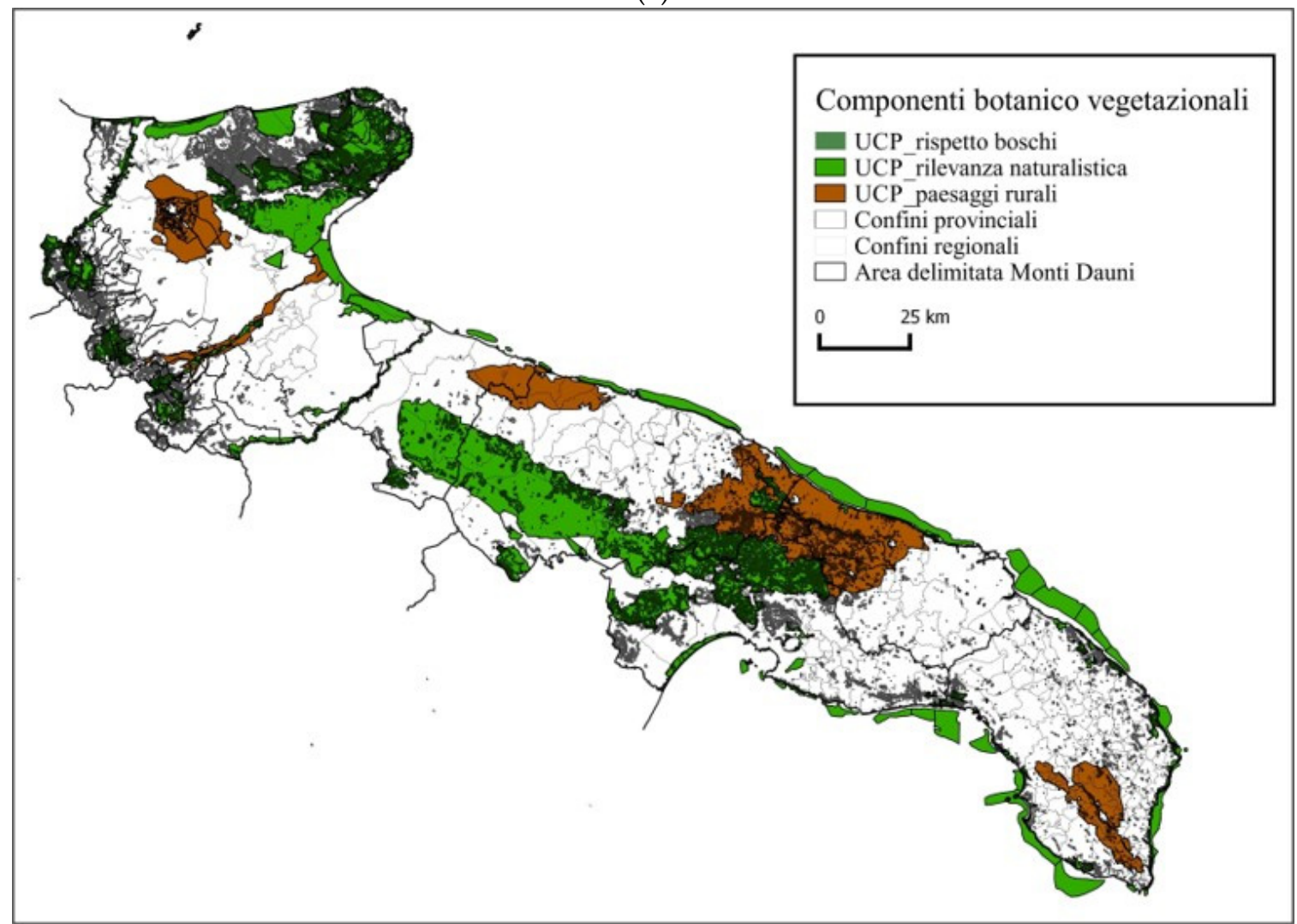

(b)

Figure 2. (a) This is an example of the first step of the mapping. The map shows the information layers concerning single objects; (b) in the next steps, the complexity gradually increases with the addition of information layers and the identification of relationships among the different data sets selected. 
As suggested by Kemp et al. [42] for the final work, the steps and goals regarding the knowledge to be acquired were expressly indicated. The students adopted the form of a written report, indicating those responsible for the different parts of the assignment, along with a group presentation. The final report, containing the maps produced and various elaborations such as graphs and tables, had to indicate and discuss the objective of the study, the method used and the results obtained. It envisaged the critical, reasoned selection of a well-defined number of documents/variables to be presented. The reports were subject to double mixed evaluation: self-assessment by the students of the process undertaken and hetero-evaluation by teachers and experts, in this case by the staff who had elaborated and written the strategy for the area under study. In the first case, a survey form was used, which was administered at the end of the course. This sheet recorded the personal strategies implemented in order to learn, tackle and accomplish the assigned task, the difficulties encountered and the strategies activated to overcome them, the personal and emotional investment in the assigned task, the individual path followed, and the main difficulties and critical issues encountered, along with the added value and limitations of the course as a whole.

The final evaluation was not limited to traditional methods, but was considered all aspects, including the personal and professional growth of the students. In the latter case, in fact, the final works were presented to key experts (figures currently involved in constructing the development strategy of the chosen area), who gave their assessments on the relevance, innovativeness, quality of knowledge and proposed interventions. The results produced not only interesting critical applications of the concepts learned through the use of GIS but also brought out further skills, competences, critical ability and a sense of active citizenship, which all developed well beyond the initial expectations.

On the formative level, interesting ideas emerged for further reflection and experimentation. More specifically, the students stressed the need to use multidisciplinary skills and knowledge in order to deepen and internalize the concepts of Geography so as to bring a mental and conceptual order to what they had learned. The aspects praised by the students were the full autonomy in choosing the variables and information needed for their final report, the support and constant discussion with the teacher, and the interest triggered in the study of a specific local context and the ongoing interventions. GIS facilitated these tasks; some of them are better specified in the Table 2 where, in correspondence with the main tasks, the students' statements on the final self-assessment form are reported. The research activity and subsequent mapping of the data triggered a range of knowledge and different skills along with increasingly challenging and precise processes of selection, reflection and reasoning. Various strategies were adopted individually in order to master the concepts learned. Due to the current pandemic situation, a continuous dialogue among the students and teacher was necessary; through dedicated work sessions, the opportunities for confrontation, discussion and brainstorming were intensified. This was an important element of the success of the experiment because it enabled problems to be overcome, from the most trivial technical ones to debates on more complex issues. The students progressed beyond the superficial learning of mere facts, as shown by the numerous in-depth studies stimulated by personal interest. The use of a self-assessment form that took into account the learning process carried out by the students was another important element of the experimentation. In fact, the possibility of describing the learning process was another element of innovation introduced, which made it possible to detect important aspects in terms of course feedback and greater awareness of one's own abilities and personal knowledge, as can be seen from the students' statements. 
Table 2. Some tasks detected in the final self-assessment form.

\begin{tabular}{|c|c|}
\hline Tasks & Students' Statements \\
\hline $\begin{array}{l}\text { Visualize the phenomena in real time to } \\
\text { acquire full awareness }\end{array}$ & $\begin{array}{l}\text { "Create maps that were able to visually represent what } \\
\text { I had in mind" }\end{array}$ \\
\hline $\begin{array}{l}\text { Understand the connections by } \\
\text { critically exploiting the potential of the } \\
\text { GIS and by bringing previous } \\
\text { knowledge into play }\end{array}$ & $\begin{array}{c}\text { "Identifying the indicators that in my view could } \\
\text { represent most of the criticalities and potential of the } \\
\text { territory" }\end{array}$ \\
\hline $\begin{array}{l}\text { Creation and systemization of a range } \\
\text { of knowledge and different skills along } \\
\text { with increasingly challenging goals }\end{array}$ & $\begin{array}{l}\text { "I also proceeded to make several attempts to modify } \\
\text { the classes so as to highlight critical issues when the } \\
\text { software had not classified the data properly; once the } \\
\text { maps were exported, I adjusted them" }\end{array}$ \\
\hline $\begin{array}{l}\text { Progressive autonomy and } \\
\text { responsibility for the learning process } \\
\text { and creation of new knowledge }\end{array}$ & $\begin{array}{c}\text { "The search for any useful information in textbooks } \\
\text { and on the web to carry out my assignment". } \\
\text { "To obtain better, more reliable information I also } \\
\text { interviewed a person with a lot of experience and } \\
\text { knowledge of the place" }\end{array}$ \\
\hline
\end{tabular}

Source: our elaboration.

Other interesting results emerged in terms of the self-assessment of the process and the emotional investment, revealing a progressive growth of skills and competences. Some students' statements follow:

- "From the comments on the maps, I began to have a critical sense and a greater awareness of the problem we were asked to tackle. The most satisfying thing was the growing understanding that came from the continuous discussion with my fellowstudents, from the consultation of the maps presented online, from the comparison, from the reading of documents. I must admit that in the end, especially after having had to deal with such a delicate issue as the Strategies in the Monti Dauni, I also felt emotionally involved. Right up to the handing-in day, the assignment seemed to be constantly evolving".

- " "I felt like a professional in the trade, satisfied with the work I was doing".

- $\quad$ "It is certainly one of the most involving courses I have done so far during my university career, because it is not just memorization of concepts, but above all application and research of everything you study".

The innovative, creative solutions that emerged were triggered by the participants' growing interest; in fact, they argued:

- $\quad$ "In the final stage, a bit like a chess player, I tried to see the problem from different points of view to identify aspects connected to the "Monti Dauni system", that could in some way help to explain more clearly the reality of the place from angles that are possibly unusual but potentially useful to find a way to fulfill the inhabitants' needs".

Based on the results obtained by all of the students (outputs capable of highlighting multiple competences and skills learned, such as the critical application of concepts and theories to a real case, the ability to elaborate a professional result in which the research method, objectives and various aspects were clear and accurate etc.) from their assessments, the course can be considered globally to have had a positive outcome; the main critical issue that emerged was the lack of time available. Based on what emerged from the selfassessment phase, the third level of critical application in the subject was fully achieved, as stated below:

- $\quad$ "The course provided me with basic and advanced skills for territorial analysis and the production of GIS cartography, with GIS application functions and techniques".

"The course strengthened my ability to solve problems, through the formulation of solutions and scenarios supported by GIS. It was an experience that certainly challenged the critical aspect of each of us, contextualizing the various approaches. 
This I can evaluate only in a positive sense, because I really appreciated the fact of leaving space for different individual thought processes".

- $\quad$ "Very interesting and stimulating, because it allowed me to travel with my mind around the places in the Monti Dauni and other inner critical areas of some regions in Italy to which I am particularly attached, which are in very similar situations. It was enlightening because it gave me a "systemic" point of view for the analysis of a territory".

The formulation and original reworking of the data and maps produced not only completed the initial context analysis developed programmatically but later prompted the students to find creative solutions and propose concrete interventions to implement in the territories. The interventions proposed ranged from specific, concrete aspects (accessibility; training; the emergence of new ways of enhancing and using local resources; new forms of tourism, such as hospitality in exchange for work; a census of public buildings to be redeveloped and allocated to the sectors of education, training and tourism), through to the construction of more complex, innovative tools (Think-tanks; Web-GIS that try to solve the main critical issues of the area, which are therefore specifically dedicated to integrating the resources and actors in the territory, especially economic operators, institutions and citizens, as users and at the same time producers of data and information). The final reports were also assessed positively by the key actors invited to speak to the students, as a way to share expert knowledge and strengthen the students' sense of belonging, making them feel part of the strategy underway in the Apulia area as active protagonists, and not simply as passive users. In other words, we progressed from mere information transmission and description of the context to the development of student empowerment. This way of working with the focus on understanding and using specific tools in a conscious manner in situations involving personal decision-making produced, among other things, conscious shared actions aimed at the greater sustainability of territorial development practices. Furthermore, this required a greater awareness of values, their internalization and their combination with other components, cognitive and otherwise.

\section{Conclusions}

The spread of GIS and the unprecedented availability of data and information are important resources for education and lifelong learning, as expressly discussed in the literature review and especially in the main international and European agendas on education for sustainable development. As previously argued, there has been such a rapid, radical spread of GIS, especially in recent years, that it has become a widely used tool in various fields and with numerous purposes. It allows the integration of spatial and non-spatial data, and - through the use of technical specifications-favours the use, selection and analysis of huge amounts of data from different sources. However, the problem of its optimal use emerges, from the point of view of applying the concepts learned and developing critical creative thinking, issues that are complex and still relatively overlooked. This aspect is fundamental because, as emerged in the main agendas, education assumes a strategic role especially for the development of fragile, vulnerable territories. In particular, it should be of good quality at all levels and for all individuals without discrimination. In the local case selected for study-defined as an inner, marginal territory-this experimentation fully entered the knowledge-building mechanism and skills needed to take advantage of opportunities and to participate fully and actively in society. As discussed in this paper, tools such as GIS are certainly of great utility and potential, and if properly used they can allow us to achieve goals that go beyond mere application. However, they are necessary but not sufficient. GIS can have a significant impact on the teaching and development of critical thinking from a sustainability perspective, but it must be placed in a context in which there is a systematic approach, starting from basic concepts of geography in an active construction of those who learn, connected to the specific learning situation and developed in a context of interpersonal communication and social collaboration. In fact, GIS considered as an isolated tool can even have the opposite effect; that is, it can lead 
to extreme reductionism and the simplification of reality rather than fostering an understanding of territorial complexity and connections from a sustainability perspective. As previously argued, at the same time as the development and multiplication of sophisticated tools of spatial analysis, with the pervasive dissemination of sources and data in an open and therefore freely usable way, we are witnessing a paradoxical situation connected to the reduction of geography teaching, especially in Italy. The combination of geographical education and information technologies applied to the territories, and the contribution they make to Sustainable Development Goals (SDG), although of strategic importance at an international programmatic level, are questions which are still under-investigated. They represent both an innovative field of experimentation and significant opportunities, especially for marginal, inner areas. In this paper, using a constructivist approach, we have tried to highlight the importance of having a solid geographical conceptual basis in order to reorganize previous knowledge, to facilitate the understanding of territorial processes, to grasp their dynamism and diversity at different scales, and to explain the effects that arise from their synergy. Starting from key concepts of geography, through material shared and discussed within the group of students, following participatory and bottom-up strategies and a path articulated in three levels-description, scientific explanation and critical application - the students were guided in the formulation of a project applied to a real local case study, exploiting the potential of GIS. This experimentation adds a further element of innovation; in fact, it was conducted in the context of a specific, real subject, with the presentation of a case study on an area of national strategic importance (Monti Dauni in the Apulia region) in the domain of development policies in the current programming cycle. This form of education, which develops awareness of place, predisposes the citizen to change, the latter being a real need that emerged in this study.

As far as GIS is concerned, it provides an excellent platform for experimentation, allowing phenomena and relationships to be visualized in real time, their causes to be explained, and aspects of previously ignored phenomena to be examined. The experimentation revealed the essential union between GIS and Geography in order to achieve educational purposes which are typical of Geography and which will be increasingly important in the immediate future, with a view to lifelong education and the training of active, responsible citizens of the future.

The key to the experimentation concerned three fundamental stages: the study and in-depth analysis of key concepts in geography, the acquisition of a representation tool (GIS, which due to its intrinsic features is capable of allowing the application of what has been learned in full autonomy), and the focus on reasoning processes. By representing the phenomena starting from a range of data; by explaining the existing relationships, transformations and dynamics; and by justifying one's choices, it was possible to facilitate the quantum leap from a passive, descriptive level of learning to a critical application and development of empowerment in the students involved. This was also possible thanks to the methods adopted in communicating the results and in the self-reconstruction of the process undertaken. The use of GIS fostered the emergence of an explorative, explanatory approach to the phenomena, also drawing on previous knowledge, prompting the search for original creative solutions (from explaining critical issues and causes through to proposals for new, basic services, for example for tourism and businesses, to connect different resources such as specific Web-GIS, innovative and multidisciplinary think-tanks, proposals for integrated itineraries of little-known local resources between coastal areas and inner and marginal areas, explaining marginalization and gender problems, and services seeking solutions for families and women in search of employment, etc.). Some interesting skills also emerged, in particular in thinking and imagining new scenarios, working in an interdisciplinary and cooperative way, cross-cultural understanding, participatory skills, planning and implementation, critical thinking, self-motivation and the motivation of others. The creation of the GIS project was therefore gradual and required various moments of reflection. This undermined the idea of automatism and the overriding technicality of the tool in favour of a conscious use based on clear knowledge and working and research 
hypotheses. This was thanks to cooperative learning, encouraging innovative ways of using data and maps, and leading students to scientific knowledge. As emerged, this is certainly not compatible with a traditional teaching and learning context, as it must be student centered, requiring the activation of more complex cognitive processes, and not a simple memorization of concepts and theories, requiring students to make greater efforts and increasing their responsibility for the achievement of the final result. In fact, the possibility of describing the learning process is another element of innovation introduced thanks to the final self-assessment form. It made it possible to detect important aspects in terms of course feedback, greater awareness of one's own learning construction process, and the identity aspects of self-construction. The approach did not envisage or take into consideration the mastery of contents alone, but instead focused above all on the way knowledge was applied, the features of the tools and artifacts specific to a real case, thereby producing positive effects on the student's sense of competence and self-efficacy. The students were able not only to critically reconstruct their own learning process but also to become aware of their own growth process, including in a professional sense. This important step gave meaning to the efforts made and is believed to have had effects on the self-awareness of the obstacles faced, and on the personal skills and strategies to face them in a process of personal growth that goes far beyond simple learning.

About the GIS, the availability of a personalized visualization of the phenomena made it possible to achieve a clearer perception and awareness of the spatial relations and of the complexity of the phenomena on different scales. The inclusion of GIS in Geography teaching therefore reveals an undoubted potential because it enables us to verify the students' authentic understanding of concepts and their application, and to expand their awareness, motivation and interest in contingent issues related to their territory, in line with international agendas in the field of sustainability education. However, as emerged in this experimentation, this type of course requires a strong personal investment by everyone; therefore, it is essential to clarify the objectives to the students from the beginning, in order to make the entire course coherent in terms of the approach adopted, starting from the teaching method to the final evaluation. Other elements that have emerged regard the need to start from basic concepts of Geography, and in general to rethink the courses of study. The basic concepts of Geography provided the basis for a strong integrated methodology using tools capable of making students reflect in order to favor the reorganization of new and previous knowledge, up to the introduction to the scientific method. About the second point, Geography represents a discipline of strong connection between different disciplinary fields, which is above all involved in understanding the complexity of the current world. The students, in fact, stressed the need to use multidisciplinary skills and knowledge in order to deepen and better internalize the concepts of Geography.

This points to the importance of innovating the courses in order to promote skills, creative and critical thinking, communication, collaboration and cooperation in the full exercise of active citizenship in practical life. In this sense, it is necessary to promote "transformative social learning" capable of deconstructing what exists, of critically reflecting on values and world views, and of affecting traditional learning processes to achieve the construction and sharing of new meanings in order to contribute to the feasibility of the goals of sustainability. However, as emerged in the experimentation, which will have to be further improved in the future, in order not to reduce their functional use, the utilization of GIS-and in general of other information technologies-must certainly be included in a non-traditional articulation of the course, with the support of the teacher as a facilitator, leading progressively to autonomy, reflexivity and critical analysis-in a nutshell, to the founding features of geographic education.

Funding: This research received no external funding.

Acknowledgments: I wish to thank the reviewers for their valuable comments on the development of this study.

Conflicts of Interest: The author declares no conflict of interest. 


\section{References}

1. Burini, F. Cartografia Partecipativa. Mapping per la Governance Ambientale e Urbana; Franco Angeli: Milano, Italy, 2016.

2. Perkins, C. Community mapping. Cartogr. J. 2007, 44, 127-137. [CrossRef]

3. Bryan, J. Walking the line: Participatory mapping, indigenous rights, and neoliberalism. Geoforum 2011, 42, 40-50. [CrossRef]

4. Chapin, M.; Lamb, Z.; Threlkeld, B. Mapping indigenous lands. Annu. Rev. Anthropol. 2005, 34, 619-638. [CrossRef]

5. Brown, G.; Weber, D. Measuring change in place values using public participation GIS (PPGIS). Appl. Geogr. 2012 , 34, 316-324. [CrossRef]

6. Goodchild, M.F. Twenty years of progress: GIScience in 2010. J. Spat. Inf. Sci. 2010, 1, 3-20. [CrossRef]

7. ISTAT. Indicatori Territoriali per le Politiche di Sviluppo; Istat: Rome, Italy, 2021. Available online: https://www.istat.it/it/archivio/ 16777 (accessed on 5 March 2021).

8. ISTAT. Gli Indicatori del BES; Istat: Rome, Italy, 2021. Available online: https:/ /www.istat.it/it (accessed on 2 May 2021).

9. Demirci, A. Evaluating the Implementation and Effectiveness of GIS-Based Application in Secondary School Geography Lessons. Am. J. Appl. Sci. 2008, 5, 169-178. [CrossRef]

10. Droogleever Fortuijn, J.; Kovács, Z.; Le Blanc, A.; O’Reilly, G.; Paul, L.; Pejdo, A. The challenges for geography in higher education in European universities. J-READING J. Res. Didact. Geogr. 2020, 1, $49-60$.

11. Álvarez Otero, J. El uso Educativo de las Infraestructuras de Datos Espaciales (IDE) para Mejorar la Responsabilidad Social de los Ciudadanos del Siglo XXI Sobre el Territorio. Ph.D. Thesis, Facultad de Educación, Departamento de Didáctica de las Ciencias Experimentales, Sociales y Matemáticas, Universidad Complutense de Madrid, Madrid, Spain, 2020. Available online: https:/ / eprints.ucm.es/id/eprint/64592/1/T42185.pdf (accessed on 2 August 2021).

12. Azzari, A.; Zamperlin, P.; Landi, F. GIS in Geography Teaching. J-READING J. Res. Didact. Geogr. 2013, 2, $27-42$.

13. Labianca, M. Towards a Visionary Approach for Rural Areas. From the Key Features to Planning the Future of LEADER; Series Perspectives on Rural Development; SIBA: Lecce, Italy, 2021; Volume 5.

14. UNESCO. Incheon Declaration and Framework for Action for the Implementation of Sustainable Development Goal 4: Ensure Inclusive and Equitable Quality Education and Promote Lifelong Learning Opportunities for All. 2015. Available online: https: / / unesdoc.unesco.org/ark:/48223/pf0000245656 (accessed on 2 August 2021).

15. Tate, N.J.; Jarvis, C.H. Changing the face of GIS education with communities of practice. J. Geogr. High. Educ. 2017, 41, 327-340. [CrossRef]

16. Tidball, K.G.; Krasny, M.E. Urban Environmental Education from a Social-Ecological Perspective: Conceptual Framework for Civic Ecology Education. Cities Environ. 2010, 3, 1-20. [CrossRef]

17. European Commission. Communication from the Commission to the European Parliament, the Council, the European Economic and Social Committee and the Committee of the Regions, 2030 Digital Compass: The European Way for the Digital Decade; 9.3.2021 COM(2021) 118 Final; EC: Brussels, Belgium, 2021.

18. UNESCO. Educazione alla Cittadinanza Globale. Temi e Obiettivi di Apprendimento; UNESCO: Parigi, France, 2018. Available online: https:/ / unesdoc.unesco.org/ark:/48223/pf0000261836 (accessed on 5 March 2021).

19. UNESCO. Operational Strategy on Youth 2014-2021; UNESCO: Paris, France, 2014. Available online: https://unesdoc.unesco.org/ ark:/48223/pf0000227150 (accessed on 5 March 2021).

20. UNESCO. Education for Sustainable Development Lens: A Policy and Practice Review Tool; UNESCO: Paris, France, 2010. Available online: https: / / unesdoc.unesco.org/ark:/48223/pf0000190898?posInSet=1\&queryId=4960eb05-ebb2-4f6b-be53-69ee2e2b06aa (accessed on 3 February 2021).

21. UNESCO. Education for Sustainable Development Goals: Learning Objectives. 2017. Available online: https: / / unesdoc.unesco. org/ark:/48223/pf0000247444?posInSet=1\&queryId=e5469dc3-5fbb-4a9f-8ea0-1418fcc196c8 (accessed on 2 August 2021).

22. UN. Transforming Our World: The 2030 Agenda for Sustainable Development; United Nations: New York, NY, USA, 2015. Available online: https://sustainabledevelopment.un.org/content/documents/21252030\%20Agenda\%20for\%20Sustainable\%20 Development\%20web.pdf (accessed on 2 May 2021).

23. UN. Global Indicator Framework for the Sustainable Development Goals and Targets of the 2030 Agenda for Sustainable Development. Adopted by the General Assembly in A/RES/71/313 (Annex), Annual Refinements Contained in E/CN.3/2018/2 (Annex II), E/CN.3/2019/2 (Annex II), 2020 Comprehensive Review Changes (Annex II) and Annual Refinements (Annex III) Contained in E/CN.3/2020/2 and Annual Refinements (Annex) Contained in E/CN.3/2021/2, 2021. Available online: https://unstats.un.org/sdgs/indicators/Global\%20Indicator\%20Framework\%20after\%202021\%20refinement_Eng.pdf (accessed on 3 August 2021).

24. Labianca, M.; De Rubertis, S.; Belliggiano, A.; Salento, A.; Navarro, F. Social Innovation, Territorial Capital and LEADER Experiences in Andalusia (Spain) and in Molise (Italy). In Neoendogenous Development in European Rural Areas. Results and Lessons; Cejudo, E., Navarro, F., Eds.; Springer: Cham, Switzerland, 2020; pp. 111-131.

25. Dematteis, G.; Giorda, C. Territorial values and geographical education. J-READING J. Res. Didact. Geogr. $2013,1,17-32$.

26. Napal, M.; Mendióroz-Lacambra, A.M.; Peñalva, A. Sustainability Teaching Tools in the Digital Age. Sustainability 2020, $12,3366$. [CrossRef]

27. Chen, S.Y.; Liu, S.Y. Developing Students' Action Competence for a Sustainable Future: A Review of Educational Research. Sustainability 2020, 12, 1374. [CrossRef] 
28. Karimi, A.; Brown, G. Assessing multiple approaches for modelling land-use conflict potential from participatory mapping data. Land Use Policy 2017, 67, 253-267. [CrossRef]

29. Ajello, A.M.; Belardi, C. Valutare le Competenze Informali; Carocci: Roma, Italy, 2007.

30. Bissanti, A.A. Geografia Attiva Perché e Come; Adda: Bari, Italy, 2005.

31. De Vecchis, G.; Palagiano, C. Le Parole Chiave della Geografia; Carocci: Roma, Italy, 2009.

32. Haggett, P. Geografia Umana; Zanichelli: Bologna, Italy, 2004.

33. Conti, S. Geografia Economica. Teorie e Metodi; Utet: Torino, Italy, 2006.

34. Fiori, M. Identità Territoriale per lo Sviluppo e L'imprenditorialità. Applicazioni Geoeconomiche d'una Metodologia Quali-Quantitativa; WIP: Bari, Italy, 2012.

35. Paasi, A. Bounded spaces in the mobile world: Deconstructing 'regional identity'. Tijdschr. Voor Econ. Soc. Geogr. 2002, 93, 137-148. [CrossRef]

36. De Rubertis, S.; Mastromarco, C.; Labianca, M. Una proposta per la definizione e rilevazione del capitale territoriale in Italia. A proposal for the definition and detection of territorial capital in Italy. Boll. Della Assoc. Ital. Cartogr. 2019, 165, $24-44$.

37. De Rubertis, S.; Fiori, M.; Varraso, I.; Ivona, A.; Grumo, R.; Labianca, M. Territorial Capital: Effects of national and regional cohesion policies. In Territorial Impact Assessment of National and Regional Territorial Cohesion in Italy. Place Evidence and Policy Orientation towards European Green Deal; Prezioso, M., Ed.; Pàtron: Bologna, Italy, 2020; pp. 65-72.

38. Vallega, A. Geografia Umana. Teoria e Prassi; Le Monnier: Firenze, Italy, 2004.

39. Department for Development and Economic Cohesion of the Ministry for Economic Development. A Strategy for Inner Areas in Italy: Definition, Objectives, Tools and Governance; MUVAL: Roma, Italy, 2014. Available online: https:/ / www.agenziacoesione.gov. it/wp-content/uploads/2020/07/MUVAL_31_Aree_interne_ENG.pdf (accessed on 3 February 2021).

40. Catizzone, A. Fondamenti di Cartografia; Gangemi: Roma, Italy, 2007.

41. Agenzia di Sviluppo dei Monti Dauni. Strategia di Sviluppo Locale "Monti Dauni. Programmazione 2014-2020", 2017. Available online: http:/ / www.montidauni2020.it/1/documenti_4048250.html (accessed on 3 February 2021).

42. Kemp, K.K.; Goodchild, M.F.; Dodson, R.F. Teaching GIS in geography. Prof. Geogr. 1992, 44, 181-191. [CrossRef] 